\title{
O êxtase de Donne
}

\author{
Artur Almeida de Ataíde
}

\section{Sobre Donne}

Entre os caminhos que mais facilmente levam hoje ao nome de John Donne (1572-1631), o título de Hemingway tem talvez primazia. For Whom the Bell Tolls, ou Por quem os sinos dobram, foi colhido pelo autor num dos escritos mais tardios de Donne, as Devotions upon Emergent Occasions, de 1624. É a mesma passagem em que se lê a conhecida fórmula "no man is an island" ("nenhum homem é uma ilha"). A essa época, Donne já seria o pastor anglicano que burilava seus sermões, e que se dedicava em seus escritos, com eficiência retórica e devoção genuína, a problemas teológicos para ele prementes, como o da unidade entre corpo e alma, por exemplo.

Mas não é demais lembrar: o mesmo Donne, nascido numa família inequivocamente católica, também foi o jovem de cujos cinco irmãos um terá sido preso por dar abrigo a um padre, enquanto outro terá largado seus estudos em Oxford pouco antes da idade em que seria obrigado a declarar sua submissão à Lei dos 39 Artigos, ou seja, à rainha Elizabeth I e à Reforma Anglicana. Foi esse mesmo jovem Donne, ainda antes de ingressar no Lincoln's Inn como estudante de direito (maio de 1592), que terá embarcado um dia com destino à Itália e à Terra Santa, mas que terminou conhecendo apenas a Itália e a Espanha: e conheceu, aparentemente, um pouco mais do que a realidade dos seus seminários e igrejas, ao menos segundo nos dá a pensar a agudeza inequivocamente mundana com que escreverá por essa época as suas primeiras elegias e sátiras, bem como o seu dia a dia movimentado, dividido entre os estudos e, provavelmente, alguns prazeres menos austeros. "A great visiter of ladies", dirá dele um de seus contemporâneos. Poucos anos depois de retornar de uma expedição a Cádiz com o Conde de Essex, e de uma busca por navios de tesouro espanhóis nos Açores com Sir 
Walter Raleigh, Donne seria preso, em 1602, por haver-se casado secretamente com a sobrinha de Sir Thomas Egerton - entre outras coisas, conselheiro da rainha Elizabeth -, de quem havia se tornado secretário. Perdendo o seu posto, Donne viverá uma década de privações com sua esposa e sua família crescente, vindo só mais tarde a recobrar alguma estabilidade financeira e alguma posição na sociedade. Até que viesse, em 1621, a se tornar deão da Catedral de São Paulo, em Londres, da qual se terá ordenado pastor e diácono ainda em 1614, e onde se encontra hoje o seu túmulo, terá sofrido a perda da esposa - dava ela a luz, no momento, ao décimo segundo filho do casal -, e terá escrito inclusive panfletos anticatólicos, além de uma intrigante refutação do suicídio como pecado - seu Biathanatos, de 1608, publicado postumamente -, bem como, claro, muitos poemas. As Devotions upon Emergent Occasions, referidas mais acima, já traziam os reflexos da doença que em poucos anos o levaria à morte.

Para leitores que acompanhem um pouco mais de perto conversas sobre poesia, um caminho tão fácil quanto o título de Hemingway serão as opiniões, bastante divulgadas, de alguns conhecidos modernos sobre seus poemas. É difícil não querer citar, por exemplo, passagens inteiras do clássico The Metaphysical Poets, em que T. S. Eliot comenta, entre outros assuntos, a complexidade das imagens de Donne, e a impregnação mútua, indissociável, que promovem entre sensorialidade e pensamento abstrato. Ezra Pound também inclui Donne em sua seleta lista de obras dignas de atenção: o seu paideuma, como hoje ainda é moda se dizer. No Brasil, na esteira de Pound, algum entusiasmo em torno do nome de Donne teve grandes divulgadores com a vanguarda concretista, tendo sido Augusto de Campos o talvez mais conhecido de seus tradutores, além de Paulo Vizioli e de Afonso Félix de Souza.

Para um olhar amplo sobre Donne e sua recepção no Brasil, além de opinião aparentemente a mais lúcida, indicação indispensável é o trabalho de José Garcez Ghirardi (John Donne e a crítica brasileira, editoras AGE e Giordano, 2000).

\section{A poesia de Donne}

Desde o visitante que, oportunamente apelidado de Klockius, anda demorando demais para deixar o prostíbulo, até a emanação invisível do amor, que, como um fio, liga dois a dois os olhos do casal de amantes que se olham (é, por isso, um fio duplo, que, pela ânsia de união dos dois, ali se entrança, e é emanação, ainda, que dos olhos ao corpo se transmite por meio de vapores espirituais tenuíssimos que interagem com o sangue): embora o espectro das realidades consideradas por Donne em seus poemas pareça corresponder à variedade e à suces- 
são de suas experiências biográficas - "sua progressiva subida ao altar", como quis um de seus comentadores -, talvez valha a pena lembrar aqui uma das percepções de Leo Spitzer em seu comentário a "The Extasie". Diz: "Donne não reencena o que vai no seu íntimo, mas aponta para algo acima dele". (A tradução é de Samuel Titan Jr., em Três poemas sobre o êxtase, Cosac \& Naify, 2003). Spitzer, na passagem, é bastante preciso: quer chamar a atenção para o fato de, no poema, a referência a uma vivência interior, talvez de se esperar ainda hoje ante um poema dito lírico, deixar-se substituir por "uma análise enciclopédica e discursiva", ou seja, pelo passeio em torno a uma realidade apenas teoricamente experienciada pelo eu lírico (no caso, o próprio "êxtase").

Tanto quanto em "The Extasie", talvez haja que se atentar para semelhante dissociação também no restante da obra de Donne. A matéria-prima biográfi$\mathrm{ca}$, ao contrário do que pudesse parecer, estaria por isso muito longe de ser a única e determinante em seus poemas, e conviveria não apenas com um poder incomum de fabulação do seu autor, mas também, e sobretudo, com seu talento especial para dotar qualquer produto do espírito de certo valor de realidade, ou mesmo, em alguns casos mais particulares, de uma espécie autônoma de existência. Com valor de realidade quer-se aqui referir a circunstancialização precisa e convincente das situações narradas, desde as mais palpáveis e possíveis, embora de constituição invariavelmente engenhosa, até as mais ostensivamente não críveis como inteiramente espontâneas, em toda a sua complexidade de imagem e raciocínio (como exemplos de um e de outro dos casos, comparem-se "The Apparition" e "Witchcraft by a Picture", respectivamente). Em tais poemas, elaboração artificiosa a posteriori e frescor presencial parecem se combinar, em discordia concors, para nos introduzir num terceiro espaço da sensibilidade - e quem ali nos guia é um matemático meticuloso, ou um filósofo analítico prolixo, que, no entanto, não perde nunca o tempo de cena, ator sempre em forma. Esse mesmo valor de realidade tem como que intensificada a sua força pela decisão da frase de Donne (assim a sentimos), pelo seu límpido "vigor coloquial" (Gardner), pelo modo natural como cada linha se deixa completar "sem esforço, e sem o desperdício de palavras ou inversões e condensações abstrusas" (Gardner). Com espécie autônoma de existência quer-se aqui referir a cerrada concatenação lógica - quando não também teológica e filosófica, ou mesmo científica - que embasa certos poemas, e a impressão de autossuficiência objetiva que enfim nos transmite: a simples verossimilhança do discurso em relação a um estado de espírito, por exemplo, deixa-se conviver no poema, em tais casos, com a verdadeira conviç̧ão de quem participa, sem dispensar as mais intricadas sutilezas de argumento, de uma disputa medieval sobre a ordem imanente das coisas. Em poemas como "The Extasie", o pra- 
zer de primeiro plano não é apenas, além dos muitos outros mais discretos, o da música do verso: é também o prazer do raciocínio que se completa.

Esses traços, que atestam a nossos olhos a mestria de Donne no fingir verbal, alimentar-se-iam, vale sempre dizer, de fontes ainda outras, para além tanto da experiência mais estritamente biográfica quanto da invenção: a referência de Helen Gardner à depravação do Ovídio dos Amores, à sentimentalidade refinada de Petrarca e às sutilidades de argumento dos neoplatônicos, prováveis leituras cativas de Donne, nos faz lembrar o quanto de convenções retóricas, de diálogos com a cultura e a tradição, mescla-se à originalidade surpreendente de tantas de suas passagens.

\section{Traduzindo Donne}

Nas próximas páginas, seguem os originais e as respectivas traduções de dois poemas e quatro epigramas de Donne. Mantivemos a métrica, o esquema de rimas e, sempre que para nós possível, também o movimento rítmico de cada verso: seu andamento mais lento ou mais ágil, a fluidez coreográfica de seus fonemas, a ondulação plástica na interação dos acentos, as vírgulas de função antes rítmica que gramatical utilizadas por Donne (algumas outras agramaticalidades, aliás, são só da tradução). Em pelo menos um dos epigramas, a perda do movimento rítmico pareceu bastante sensível. Em "Loves Growth" talvez se tenha conseguido razoável média: o primeiro verso e o último talvez sirvam de bom exemplo; os versos 10 e 21 talvez sejam casos em que diferença não implicou, necessariamente, alguma perda; e o verso 20, em contrapartida, é um que nos deixa com saudade da força rítmica do original, assim como de seu sentido mais preciso, restando-nos desejar que se integre sem distúrbios - também aos ouvidos de quem leia - à harmonia do conjunto.

Quanto a "The Extasie", apenas na segunda estrofe o esquema de rimas foi alterado (em vez de $\mathrm{ABAB}$, ficou $\mathrm{AABB}$ ), mas o nível de exigência foi o mesmo, havendo-se mantido o octossílabo em todo o texto (em pelo menos um caso, no entanto, convoca-se a benevolência articulatória do leitor). Embora a prática de se aumentar o metro em duas sílabas, ao se traduzir do inglês para o português, pareça sempre justificável diante da profusão de monossílabos do inglês, a disposição de um conteúdo complexo em versos rápidos e leves foi um traço de que não quisemos abrir mão. À medida que o desafio talvez tenha se tornado maior - podemos ser elípticos, mas não lacunares -, também aumentaram as chances de se conseguir a precisão das fórmulas de Donne, a perfeição com que se fecham sem palavras demais, como disse Gardner, ou rigorosamente 
com as palavras certas, por não restar espaço para quaisquer outras. Quanto a esse aspecto, talvez valha a pena, aqui, demorar-se mais um pouco.

$\mathrm{Na}$ tradução de Augusto de Campos, a única a que tivemos acesso, a opção por decassílabos em lugar dos octossílabos do original é o que pode ter dado ensejo ao aparecimento de certo excedente discursivo; em alguns momentos, esse excedente chega a quase transformar tradução em explicação, ou a transformar em explicação, de tom inclusive entre sentencioso e áulico ( $c$. abaixo), o que no original são, sim, os delírios teóricos de um eu lírico, mas que, em virtude de sua agilidade verbal e de sua atenção ao "tempo de cena", como dissemos antes, somos ainda compelidos a perceber como fala de um narrador, e um narrador, frise-se, in loco, sem muito tempo, por exemplo, para "por isto", "ao contrário" etc.:

E nós, que somos essa alma jovem

Nossa composição já conhecemos

Por isto: os átomos de que nascemos

São almas que não mais se movem. (v. 45-48)

Ao contrário, devemos ser-lhes gratas

Por nos (a nós) haverem atraído,

Emprestando-nos forças e sentidos:

Escória, não, mas liga que nos ata. (v. 53-56)

O leitor mais interessado pode confrontar mais tarde os trechos correspondentes em nossa tradução; temos a impressão de que conseguimos ao menos amenizar esse problema (provavelmente criando outros).

Mais premente que a questão métrica, no entanto, nos pareceu a necessidade de se buscar na tradução, não importa qual seja o metro, uma força rítmica compatível com o movimento decidido dos versos de Donne. Embora Augusto de Campos nos tenha dado decassílabos tão harmônicos quanto estes:

Nova sublimação tomar do instante

E retornar mais puro do que antes. (v. 27-28)

Há estrofes em que a métrica, sim, está presente, mas não a integração em música: 
Assim as almas dos amantes devem

Descer às afeições e às faculdades

Que os sentidos atingem e percebem,

Ou um Príncipe jaz aprisionado. (v. 65-68)

De todos os aspectos dos poemas traduzidos, a esse procuramos dedicar nosso maior cuidado. Para a aferição desse tipo de coisa, nada melhor do que a leitura verso a verso em voz alta, além do impaciente conselho de Pound: "ATENTE para o som que isso faz" (na tradução de José Paulo Paes e Augusto de Campos do $A B C$ da literatura, pela Cultrix).

Deixando de lado o aspecto sonoro, veja-se um problema que não conseguimos evitar em pelo menos uma de nossas estrofes. Também na versão de Augusto de Campos o encontramos. Nos trechos abaixo, os grifos marcam palavras que nos parecem despertar associações algo dispersivas; através delas, campos semânticos díspares são trazidos para o poema arbitrariamente, quer dizer, sem quaisquer outras motivações para tanto no contexto imediato do texto, ou sem que haja um desenvolvimento seu numa rede metafórica consciente e articulada ( $c f$.v. 60 da nossa tradução). Cremos ser uma espécie de descontrole que Donne não praticaria, e que não parece haver, em todo caso, em "The Extasie":

\section{E modelar nos olhos as figuras}

A nossa única propagação. (v. 11-12)

A alma que dessas duas brota

À magra solidão derrota. (v. 43-44)

Aos corpos, finalmente, retornemos,

Descortinando o amor a toda a gente; (v. 69-70)

etc.

Nos trechos que seguem, o problema é semelhante. Tem a ver mais uma vez com o controle vocabular de Donne: ao se substituir sua precisão quase que terminológica por aproximações, sem uma atenção cuidadosa aos contextos tanto textual quanto cultural, o sentido sutil de algumas passagens pode sair prejudicado. Estes são alguns exemplos, cujo sentido mais preciso, se não o tivermos recuperado na nossa própria tradução, talvez seja elucidado nas notas que a completam: 
E nós, que somos essa alma jovem (v. 45)

São almas que não mais se movem. (v. 48)

Escória, não, mas liga que nos ata. (v. 56)

Pois tais dedos carecem de apertar

Esse invisivel nó que nos faz homens, (v. 63-64)

etc.

(Para conferir o texto completo da tradução de Augusto de Campos, o livro com o ensaio de Spitzer a traz em versão bilíngue; também se encontra na edição do $A B C$ da literatura pela Cultrix e em obras do tradutor, como $O$ anticrítico. Outra tradução, de Paulo Vizioli, pode ser lida em seu John Donne, o poeta do amor e da morte, J. C. Ismael Editor, 1985.)

\section{Dois êxtases?}

Um último ponto aqui oportuno, ainda acerca de "The Extasie", é a polêmica sobre seu suposto sentido geral. Ezra Pound, por exemplo, ao resumir o poema, é enfático: "é o platonismo acreditado" ("platonism believed"). Do verso 49 em diante, no entanto, há que se perceber no poema uma discreta guinada: Donne cessa a descrição extasiada e extasiante da fusão das almas para dar início ao que parece uma defesa dos direitos do corpo. Gardner menciona que a associação entre esses dois assuntos, embora nos possa parecer digressiva a uma primeira vista, era uma prática na verdade frequente em textos neoplatônicos italianos e franceses. Para Grierson, em virtude dessa articulação com o corpo, o que haveria em "The Extasie", diferentemente do que diz Pound, seria o platonismo "modificado e transcendido, e talvez não completamente acreditado", conclusão a que terá chegado com base também em outros poemas, e que o levaria à interpretação do platonismo mais puro de algumas passagens de Donne antes como recurso literário do que como convicção filosófica. Gardner, ainda, com base também noutros poemas, interpreta a volta final das personagens ao corpo como concessão altruísta do casal: reassumindo a condição normal de todo humano, isto é, a de ser indissociavelmente alma e corpo, e dando continuidade a seu viver comum e cotidiano, ambos poderiam tornar manifesta a outros, através de seus 
atos corriqueiros, a fusão exemplar de suas almas, sumo Bem que de outro modo permaneceria invisível e secreto. Pierre Legouis, no polo oposto ao de Pound, e em desacordo com a leitura de Gardner, interpreta o poema como um convite advertidamente oblíquo, sinuoso, à consumação do ato sexual: a sua primeira parte, nesse caso, constituiria o mais laborioso dos estratagemas um dia já forjados por um galanteador ante uma dama, dama que ele de antemão já saberia propensa a platonismos, e por isso o discurso. Spitzer, contra Legouis, e aproximando-se às posições mais moderadas de Grierson e Gardner, argumenta que o tom da parte inicial do poema, no entanto, dificilmente poderá ser confundido com o da hipocrisia; sobre a segunda parte, aliás, embora reconheça o brilho isolado de alguns dos versos, Spitzer fala em "anticlímax", e chega a conjeturar sobre uma escritura mais tardia do trecho, que considera inferior.

O problema, salvo engano, permanece sem resposta conclusiva. O texto de Donne parece suficientemente ambíguo e tensionado para que, defensavelmente, comporte cada uma das diferentes leituras (mais umas que outras, em nossa opinião). O leitor, então, sinta-se livre para encontrar a sua, assim como em suas mãos também deixaremos o trabalho de descobrir como um dos nossos versos, por pura falta de opção, inclina-se mais que o original em direção a uma dessas várias interpretações (em todo caso, sinalizamos nas notas a ocorrência). Ainda quanto a esse aspecto: na tradução de Augusto de Campos, o verso 49 precisamente o que dá início à segunda parte do poema - constitui uma apóstrofe: "Mas que distância e distração as nossas!". Cremos possível lê-la em apenas duas claves: uma é completamente ingênua; a outra, completamente cínica. Nenhum dos dois casos nos parece compatível com a sofisticação ou complexidade tonal de "The Extasie", sofisticação essa sem a qual talvez não houvesse ensejo para a polêmica. Esse, no entanto, é mais um exame que deixamos a cargo do leitor.

À parte a polêmica, mas ainda em estreita relação com a questão do par corpo-alma, Spitzer sugere um paralelo interessante: de um lado, a incompatibilidade entre Donne e a teorização do amor como realidade puramente espiritual; de outro, a incompatibilidade entre a crença católica na transubstanciação do pão e do vinho - a presentificação também corpórea de Cristo no ritual da missa - e o protestantismo, que a renega. Constituirá a segunda parte de "The Extasie", dedicada ao corpo, a expressão de uma íntima e discreta revanche católica, consciente ou não, do espírito de Donne e de sua formação, como um refluxo ressublimado da cultura? Fica o paralelo.

No que diz respeito ainda, por fim, a dificuldades tradutórias - mas não mais a "The Extasie" -, uma última nota: num dos epigramas, a ocorrência de um 
trocadilho, destacado no original em tipos itálicos (recurso também utilizado na tradução), faz da nossa versão apenas um atestado de fracasso ante o engenho de Donne; trata-se de um exemplo, ao mesmo tempo, do abismo entre línguas com que se confronta, eventualmente, quem traduz.

Dois poemas e quatro epigramas: esperamos um dia poder aumentar esse grupo, mas por ora é o que temos. Serve como pequena - muito pequena amostra da pluralidade da obra de Donne. Mais do que debitária de um modo inescapavelmente parcial de ler um dado texto, a tradução de poesia é debitária de um parcial modo de gostar de um dado texto: as miragens inerentes ao exercício desse gostar - "transforma-se o amador na coisa amada" - levariam a extremos ainda maiores o arbitrário latente de toda solução tradutória, de qualquer tempo e lugar. Embora se trate, desse modo, de traduções de um leitor admirado, antes de tudo, e não de um especialista, o leitor que tiver problemas para compreender certas passagens talvez possa encontrar algum socorro nas notas incluídas ao fim, já referidas. Assim como as informações biográficas sobre Donne, o conteúdo dessas notas foi baseado nas introduções (e nas notas) de Sir Robert Grierson em Donne: Poetical Works, de 1933, e de Helen Gardner, em The Elegies and the Songs and Sonnets, de 1965, ambos publicados pela Oxford University Press.

A tradução de "The Extasie", com algumas diferenças, foi publicada pela primeira vez no segundo número da Crispim - revista de crítica e criação literária, em 2007 (www.revistacrispim.com.br).

\section{The Extasie}

WHERE, like a pillow on a bed,

A Pregnant banke swel'd up, to rest

The violets reclining head,

Sat we two, one anothers best.

Our hands were firmely cimented

With a fast balme, which thence did spring,

Our eye-beames twisted, and did thred

Our eyes, upon one double string; 
So to'entergraft our hands, as yet

Was all the meanes to make us one,

And pictures in our eyes to get

Was all our propagation.

As 'twixt two equal Armies, Fate

Suspends uncertaine victorie,

Our soules, (which to advance their state,

Were gone out,) hung 'twixt her, and mee.

And whil'st our soules negotiate there,

Wee like sepulchrall statues lay;

All day, the same our postures were,

And wee said nothing, all the day.

If any, so by love refin'd,

That he soules language understood,

And by good love were growen all minde,

Within convenient distance stood,

He (though he knew not which soule spake,

Because both meant, both spake the same)

Might thence a new concoction take,

And part farre purer then he came.

This Extasie doth unperplex

(We said) and tell us what we love,

We see by this, it was not sexe,

We see, we saw not what did move:

But as all severall soules containe

Mixture of things, they know not what,

Love, these mixt soules doth mixe againe,

And makes both one, each this and that. 
A single violet transplant,

The strength, the colour, and the size,

(All which before was poore, and scant,)

Redoubles still, and multiplies.

When love, with one another so

Interinanimates two soules,

That abler soule, which thence doth flow,

Defects of lonelinesse controules.

Wee then, who are this new soule, know,

Of what we are compos'd, and made,

For, th'Atomies of which we grow,

Are soules, whom no change can invade.

But $\mathrm{O}$ alas, so long, so farre

Our bodies why doe wee forbeare?

They'are ours, though they'are not wee, Wee are

The intelligences, they the spheare.

We owe them thankes, because they thus,

Did us, to us, at first convay,

Yeelded their forces, sense, to us,

Nor are drosse to us, but allay.

On man heavens influence workes not so,

But that it first imprints the ayre,

Soe soule into the soule may flow,

Though it to body first repaire.

As our blood labours to beget

Spirits, as like soules as it can,

Because such fingers need to knit

That subtile knot, which makes us man: 
So must pure lovers soules descend

T'affections, and to faculties,

Which sense may reach and apprehend,

Else a great Prince in prison lies.

To'our bodies turne wee then, that so

Weake men on love reveal'd may looke;

Loves mysteries in soules doe grow,

But yet the body is his booke.

And if some lover, such as wee,

Have heard this dialogue of one,

Let him still marke us, he shall see

Small change, when we'are to bodies gone.

\section{O Êxtase}

ONDE, almofada numa cama,

A margem Fértil cresce e ampara,

Pensa, a violeta que descansa,

$\mathrm{O}$ amor um do outro a dois sentava:

Tu e eu, as mãos encimentadas

Do leve bálsamo nas palmas,

E olhos - de olhares enlaçados -

Por dupla linha alinhavados.

Além de mãos no enxerto mútuo

- Nos era tudo a unir então -

Reter nos olhos o minuto

Era a tão só propagação.

Como, a iguais Armadas, o Fado

Suspende o inesperado fim, 
As almas, avançando o estágio,

Pairavam fora, entre ela e mim.

E o corpo, as almas em congresso,

Como anjo sepulcral, jazia;

$\mathrm{O}$ dia inteiro o mesmo gesto,

E sem falar, por todo um dia.

Se alguém, do Amor tão sublimado

Que de almas entendesse a língua,

Em pura mente transmudado,

Distasse quanto a ouvir convinha,

Ali (sem ver quem lhe falava,

Pois de ambas escutava o mesmo)

Tão nova confeição provara,

Que iria mais puro do que veio.

Tal Extase revela o nexo

(Dissemos) do que nós sentimos;

Por ele vemos: não é sexo,

Por ele vemos: é invisível;

Pois tendo as almas, sendo elas,

Mesclas de coisas, de insentidos,

O Amor, a mesclas, vem e remescla,

Faz duas uma, e isto aquilo.

A violeta transplantemos,

E a força, a cor, o porte e a vida

( $\mathrm{E}$ tudo o mais que fenecendo)

Redobra ainda, e multiplica.

40

Se Amor, uma alma com mais uma

Interinanimiza as duas, 
Mais una, a que dali reflua

A falta e a solidão regula.

E em nós, nessa alma, descobrimos

O que nos fez e nos formara:

Que os Átomos de que provimos

São almas, a mudar contrárias.

Mas oh, alas!, tempo tão longo

Os corpos que razão renega?

São nossos, não nos são; nós somos

Inteligências, não Esferas.

Devemos graças por primeiro

Nos darem, sós, à nossa vista;

Se as suas forças nos cederam,

Não são escória, são a liga.

Somente, em nós, os céus influem

Se o ar se imprime à nossa volta,

Pois almas uma noutra afluem

Se vão aos corpos, nossa porta.

Como age o sangue a produzir

Espíritos (que em nós se somem:

Pois esses dedos têm de urdir

O nó sutil que nos faz homens),

A alma amante assim descende

Às faculdades e aos desejos,

E por sentidos se apreende,

Ou grande Príncipe jaz preso.

Aos corpos regressemos, onde

Os fracos o notar consigam: 
Se nas almas seu milagre esconde,

Dos corpos faz amor seu livro.

Se algum amante nos ouviu

No então diálogo de um,

Nos veja, pois dirá que viu,

Distinto um do outro, corpo algum.

\section{Loves growth}

I SCARCE beleeve my love to be so pure

As I had thought it was,

Because it doth endure

Vicissitude, and season, as the grasse;

Me thinkes I lyed all winter, when I swore,

My love was infinite, if spring make'it more.

But if this medicine, love, which cures all sorrow

With more, not onely bee no quintessence,

But mixt of all stuffes, paining soule, or sense,

And of the Sunne his working vigour borrow,

Love's not so pure, and abstract, as they use

To say, which have no Mistresse but their Muse,

But as all else, being elemented too,

Love sometimes would contemplate, sometimes do.

And yet no greater, but more eminent,

Love by the spring is growne;

As, in the firmament,

Starres by the Sunne are not inlarg'd, but showne,

Gentle love deeds, as blossomes on a bough,

From loves awakened root do bud out now.

If, as in water stir'd more circles bee

Produc'd by one, love such additions take, 
Those like so many spheares, but one heaven make, For, they are all concentrique unto thee;

And though each spring doe adde to love new heate,

As princes doe in times of action get

New taxes, and remit them not in peace,

No winter shall abate the springs encrease.

\section{O crescimento do amor}

NÃo creio mais o amor me ser tão puro

o quanto diz a fama;

que sofra não recuso

vicissitude e ciclos, como a grama;

pareço haver mentido o inverno inteiro

que fosse eterno: o Sol pôde acrescê-lo.

Se tal fármaco, o amor, me cura os danos crescendo-os, quintessência ele não sendo, mas soma de mil coisas, de alma e senso; se ao Sol de empréstimo ele toma o tônus, não é tão puro e abstrato como o julga alguém que não tem dama além da Musa; pois nele havendo, como em tudo há partes, o amor não só contempla, às vezes age.

Mas não maior, e sim mais eminente,

o Amor na primavera;

se só mais claramente

a estrela ao Sol se mostra, e não se altera, gestos de amor, como botões num ramo, nutrindo-se a raiz só estão viçando.

Se, como em água um círculo a surgir após o outro, acréscimos se dão, esferas de um céu único eles são, 
pois todos são concêntricos em ti;

e se o amor ao Sol se vê mais novo,

qual príncipes, que imposto sobre imposto

nos cobram, quando em guerra ou quando é tempo,

inverno algum detém do amor o aumento.

\section{Epigrams}

A selfe accuser

Your mistris, that you follow whores, still taxeth you:

'tis strange that she should thus confess it, though'it be true.

A licentious person

Thy sinnes and haires may no man equall call,

For, as thy sinnes increase, thy haires doe fall.

A lame begger

I am unable, yonder begger cries,

To stand, or move; if he say true, hee lies.

Klockius

Klockius so deeply hath sworne, ne'r more to come

In bawdie house, that hee dares not goe home.

\section{A burnt ship}

Out of a fired ship, which by no way

But drowning could be rescued from the flame,

Some men leap'd forth, and ever as they came

Neere the foes ships, did by their shot decay; 
So all were lost, which in the ship were found,

They in the sea being burnt, they in the burnt ship drown'd.

\section{Epigramas}

Uma autoacusação

A esposa, de que andais com putas, fez a queixa:

Estranho que o assim confesse, embora o seja.

Uma pessoa licenciosa

Teus pelos e pecados, iguais te não são;

Se mais pecados vêm, teus pelos mais se vão.

Um pedinte aleijado

"Não sou capaz", assim diz ele sempre,

"De erguer-me e andar": jazeria somente.

Klockius

Tanto jurou que não vem mais à porta

Do bordel, que pra casa nem mais volta.

Um barco em chamas

Dum barco já batido e sem socorro,

Que apenas naufragando escapa ao fogo,

Saltaram uns, que aos barcos inimigos

Indo a nado, queimaram sob os tiros.

$\mathrm{E}$ assim daquele barco morrem todos:

Uns queimam-se no mar, e afogam-se uns no fogo. 


\section{Notas}

\section{"The Extasie"}

v. 4 Jogo lógico inexistente no original, introduzido por não se haver conseguido melhor solução. Talvez se torne menos imperdoável por parecer em harmonia com o estilo de Donne: ou assim parece, ao menos, a um leitor lusófono contaminado pelo Fernando Pessoa de "Análise" e do "baste a quem baste o bastante de lhe bastar", ou pelo Camões que prega peças com os sentidos da palavra "pena".

v. 7-8 Uma paráfrase menos concisa dessa imagem pode ser encontrada no segundo tópico da nossa introdução.

v. 11 Essa tradução do verso faz perder de vista a imagem precisa do original, que ocorre noutros poemas de Donne. Segundo Gardner, que optou pela forma "pictures on our eyes to get", o verso faz referência ao fato de cada um dos amantes ter a sua imagem refletida nos olhos do outro.

v. 33-34 Atente-se para a teoria do eu que se insinua nessa e noutras passagens da obra de Donne: um eu repleto de coisas que mal sabemos, um mundo interno plurívoco e complexo. É uma noção que comparece, segundo Gardner, em Leone Ebreo (aprox. 1460-1530), um dos teóricos renascentistas do amor.

v. 47 "Átomos", aqui, valeria com o sentido mais geral de, simplesmente, partes constitutivas, componentes.

v. $52 \mathrm{Na}$ cosmologia aristotélica, os planetas eram compostos de uma "esfera" e da "inteligência" responsável por movê-la, uma não existindo sem a outra. Leone Ebreo ( $c f$. acima) fala da relação entre corpo e alma, no amor, como semelhante àquela entre esfera e inteligência.

v. 56 A metáfora, inspirada na química ("escória" e "liga"), alude às teorias sobre o amor que relegavam o corpo a um segundo plano, como a contraparte espúria do amor verdadeiro (aquele que se consumava platonicamente entre as almas).

v. 58 Para a medicina hermética (Gardner cita Paracelso), o ar mediava a influência das estrelas sobre nós; Donne, em "Air and Angels", diz que os anjos vestemse de ar. As forças espirituais, para se fazer entender frente aos humanos, precisariam se deixar mediar pela matéria impura do mundo - exatamente como, aliás, funcionaria no amor a dialética entre a alma e o corpo dos amantes.

v. 61-64 Para a fisiologia da época, o sangue era o responsável por ligar o corpo à alma: os "espíritos" por ele produzidos atuavam como sutis emissários do corpo; sendo os únicos capazes de adentrar os domínios da mente pura, traduziam o 
corpo em alma, e a alma em corpo. O sangue, portanto, seria o autor do "nó sutil" entre corpo e alma, o "nó" que nos faz humanos.

v. 76 Embora a formulação possa parecer adequada, considerando-se o dito na nota ao v. 4, o resultado talvez carnalize um pouco além do necessário a volta ao corpo que fecha o poema. Embora tendamos pessoalmente a concordar com o argumento de Spitzer (ou Pound) sobre o tom da primeira metade do poema, e a crer, com Gardner, que o êxtase seja, sim, o seu centro, e não um mero pretexto, a nossa tradução desse verso, não por opção, talvez esteja mais ao gosto de Legouis ( $f$. terceira parte da introdução).

\section{"Loves Growth"}

v. 1-2 Donne aqui se reporta às concepções platonizantes do amor, em que este é pura essência, ideia eterna sempre igual a ela mesma; o amor pensado antes como entidade metafísica do que como realidade psicológica.

v. 5-6 Parece haver mentido porque, se de fato fosse "eterno", como poderia ter se tornado ainda maior?

v. 17-20 Donne aqui se referiria ao fato (?) de as estrelas brilharem mais quando perto do Sol, parecendo maiores. Note-se nessa passagem o encadeamento dos símiles: do mesmo modo como as estrelas não mudam sua essência, mas apenas sua aparência, assim também os botões de flor no ramo, que apenas desabrocham.

v. 21-24 Mais uma vez, note-se a imbricação de símiles: os círculos concêntricos e sucessivos que surgem numa superfície d' água - quando atingida por uma pedra, por exemplo -, além de servirem a Donne como símile para os sucessivos aumentos do amor, terminam por remetê-lo à estrutura do universo, segundo a teoria ptolomaica: no centro de tudo estava a Terra, circundada por nove esferas concêntricas - os nove "céus" -, cada qual com seu "planeta" correspondente, incluindo-se sob esta denominação também o Sol e a Lua. Essa estrutura é comparada àquela que rege a dinâmica de expansão do seu amor ( $f$. o v. 52 de "The Extasie", em que, noutros termos, o mesmo paralelo ocorre): assim como ali constitui a Terra o centro inalterável de tudo, assim é sua dama, regente do seu amor como do universo. Nos versos seguintes, outro salto nos desconcerta, como contraponto ousadamente pedestre às alturas e à pureza desses últimos: Donne utiliza como símile para o crescimento do amor o aumento dos impostos. 


\section{Referências}

CAMPOS, Augusto. O anticrítico. São Paulo: Companhia das Letras, 1986.

ELIOT, T. S. "The Metaphysical Poets". In: Poems and Prose. New York, Toronto: Alfred Knopf, 1998.

GARDNER, Helen. (org.) The Elegies and the Songs and Sonnets. Oxford: Clarendon Press, Oxford University Press, 1965.

GHIRARDI, José Garcez. John Donne e a crítica brasileira: três momentos, três olhares. Porto Alegre, São Paulo: AGE, Giordano, 2000.

GRIERSON, H. (org.) Donne: Poetical Works. New York, Toronto: Oxford University Press, 1967 [1933].

POUND, Ezra. ABC da literatura. Trad. Augusto de Campos e José Paulo Paes. 9 ed. São Paulo: Cultrix, 2001.

SPITZER, Leo. Três poemas sobre o êxtase: John Donne, San Juan de la Cruz, Richard Wagner. Trad. Samuel Titan Jr. São Paulo: Cosac \& Naify, 2003. 